\title{
Urbanisation and Economic Development in Bosnia and Herzegovina
}

\author{
Rahman Nurković \\ University of Sarajevo, Sarajevo, Bosnia and Herzegovina
}

\begin{abstract}
The fundamental characteristics of urbanisation and economic development of Bosnia and Herzegovina at the end of 19th, and at the beginning of 20th century, have been discussed in the paper. The recent developmental urban processes have been considered through three groups of indicators: demographic, regional and socio-geographic development. Based on results of the surveys conducted in the regional economic centres in Bosnia and Herzegovina in 2011, a development of urban functions in the urban centres has been shown. It has been proved that the dominant tertiary activities have a big importance and an intensive influence on urban and economic development in all urban settlements. The research included a theoretical part within which the literature on urban and economic development of settlements has been searched. For needs of the research, eight economic centres in Bosnia and Herzegovina were chosen. Analysis of the obtained results shows a different level of urbanisation in Bosnia and Herzegovina with particularly separated larger and asymmetrically distributed urban centres: Sarajevo, Tuzla, Mostar, Banja Luka, Zenica, and Bihać. The mentioned urban and economic centres are distributed along the major traffic communications. The settlements in east and west part of Bosnia and Herzegovina, in which a traffic network is poorly developed, have a lower urbanisation level. The obtained data proved the existence of a traditional difference and a different level in development of particular regions and total economy in Bosnia and Herzegovina. Low urbanisation level of a large number of settlements in Bosnia and Herzegovina, is in direct connection with economic development and density of those settlements. The achieved urbanisation level with an overall economic development is characteristic of Bosnia and Herzegovina and of the other countries in its surroundings as well.
\end{abstract}

Keywords: urban population, economy, urbanisation, economic development, urban centres, regional development

\section{Introduction}

Every country and every region urbanise gradually and the intensity and forms of urbanization change over the time with socio-economic development. Owing to its functions urbanisation has, as it is often emphasized, a focal importance in the space in which it is located. Such form of urbanisation and economic development, naturally, with certain specificities is characteristic of our developing country (Ptacek, 2008).

Rahman Nurković, Ph.D., Associate Professor of Geography, Faculty of Natural Sciences, Department of Geography, University of Sarajevo.

Correspondence to this article should be addressed to Rahman Nurković, Department of Geography, Faculty of Natural Sciences, University of Sarajevo, Bosnia and Herzegovina. E-mail: rahmannurkovic@hotmail.com. 
The rapid growth of the population in the urban settlements and rural exodus, like a side effect, has certain results that arouse attention and require specific interventions of the society. It is thought that economic forces have a dominant influence on urban and economic development of cities in Bosnia and Herzegovina. Along with material production, the towns are bearers of service activities. In addition to industry, these are commerce, school system, health care, administration, banking, and insurance, etc.. Population of the surrounding spaces satisfies many vital needs in the cities, but the population of cities is also provided with many food items from the surroundings. Therefore, there are complementary functional relations between a city and the surrounding area. Intensity of the functional connection of the city and the surrounding area weakens, as a rule, with increasing the distance from the city (Vresk, 1990).

However, processes in the world that change the tendencies of urban and economic development of Bosnia and Herzegovina strengthened in the past 20 years. Most of our areas are still in the urbanisation stage that is characterised by strong polarisation, i.e., a rapid growth of cities as a consequence of concentration of jobs and migration of the population from the village.

Such urbanisation form, naturally, with certain specificities is characteristic of all countries in the stage of industrialisation (Pacione, 2001). A rapid growth of urban population and rural exodus as a result affect certain occurrences, which arouse attention and require specific interventions of the society. These are, on the one hand, problems in the cities that are created by overemphasized and frequently uncontrolled concentration (high population density, unemployment, illegal construction, pollution etc.), and problems arising in rural environments (population aging, appearance of old people's households, production extensification, appearance of uncultivated soil etc.).

\section{Socio-economic Transformation and Regional Development of Bosnia and Herzegovina}

The most dynamical socio-economic development of Bosnia and Herzegovina was ongoing under influence of widespread industrialisation. Dynamical course of the second half of the 20th century has not reflected on growth of physical volume of work function as much as it has reflected on a change of socio-economic structure of population (Lorber, 2009). Level of socio-economic transformation and employment, as well as their spatial differences should be observed in connection with a network of work centres and significance of work functions of single centres in Bosnia and Herzegovina.

It is interesting, though, that cities and centres of work in order of size have similar characteristics, but some cities replaced the places in the system. Asymmetrical distribution of centres in the network should be, however, particularly emphasized regarding importance of function of economic work centres, as well as unequal urban density of network of settlements. Sarajevo, as the strongest work centre has been positioned on the edge in the network, and in single parts of the area there is a lack of stronger work centres. It is particularly noticeable in eastern part of central Bosnia and Herzegovina. Besides the asymmetry, in regard to size of work centres density of urban centres is also unequal.

According to density of network, an area of central Bosnia and Herzegovina is distinguished, and traffic lines toward Zenica and Doboj as well. However, the poorest network of centres is observed in east Bosnia and Herzegovina. This will, certainly, reflect on single directions, in particular on intensity and forms of urbanisation. In 1991, large industrial work centres were dominant in Bosnia and Herzegovina. Stronger work centres had a 
particular importance for development of continuous urbanised zones.

In 1991, there were five such centres. Sarajevo is the largest work centre, with more than 184,674 or $46.9 \%$; Banja Luka 65,026 or $16.2 \%$, Zenica 54,991 or $13.7 \%$, and Tuzla 51,852 or $12.9 \%$ of total employed population in Bosnia and Herzegovina. Today's indicators in 2011, in total number of employed population in regional centres of Bosnia and Herzegovina indicate deep crisis of economic activities.

In 2011, number of employed population decreased almost to the 1971 level. Thus, Sarajevo is still the largest work centre, with more than 94,165 or $28.0 \%$, Banja Luka 54,622 or $16.2 \%$, Tuzla 60,994 or $18.1 \%$, and Zenica 54,622 or 16.2\% of total number of employed people in Bosnia and Herzegovina. In 2011, Sarajevo is still the largest city (see Table 1).

Table 1

Centres According to Number of Workers in Economy From 1991 to 2011

\begin{tabular}{|c|c|c|c|c|c|c|}
\hline Centres & $\begin{array}{l}\text { Employed in } \\
\text { economy in } 1991\end{array}$ & $1991(\%)$ & $\begin{array}{l}\text { Employed in economy } \\
2002 \text { (Estimation) }\end{array}$ & $\begin{array}{l}2002 \text { (Estimation) } \\
(\%)\end{array}$ & $\begin{array}{l}\text { Employed in economy } \\
2011 \text { (Estimation) }\end{array}$ & $\begin{array}{l}2011 \text { (Estimations) } \\
(\%)\end{array}$ \\
\hline Sarajevo & 184,674 & 46.9 & 185,873 & 41.0 & 94,165 & 28.0 \\
\hline Mostar & 44,124 & 11.0 & 57,878 & 12.7 & 54,622 & 16.2 \\
\hline Banja Luka & 65,026 & 16.2 & 67,345 & 14.8 & 70,958 & 21.1 \\
\hline Zenica & 54,991 & 13.7 & 69,163 & 15.2 & 54,622 & 16.2 \\
\hline Tuzla & 51,852 & 12.9 & 72,856 & 16.0 & 60,994 & 18.1 \\
\hline Total & 400,667 & 100 & 453,115 & 100 & 335,361 & 100 \\
\hline
\end{tabular}

In the structure of smaller work centres a lack of centres with work function from 2,000 and more employed people is noticed. In their development in period from 1991 to 2008, urban cores of Bosnia and Herzegovina obtained the character of relative decentralization. Suburban settlements express faster tendency of increase in number of population.

Due to expanding the industrial firms, these settlements experience increasingly stronger functional transformation. In order to evaluate the suburbanisation level in Bosnia and Herzegovina, settlements are differentiated according to socio-economic changes into four categories: urban settlements, stronger urbanised settlements, less urbanised settlements and rural settlements.

Judging of dynamics of increase in jobs in the network of work centres, there won't be any significant changes soon. In the period from 1991 to 2011, the highest increase in jobs had some suburban centres of Sarajevo etc.. These data indicate increase of significance of work function of the Zagreb agglomeration with certain redistribution of jobs in favour of the surroundings. This is, as it has been ascertained, in accordance with development of metropolitan region of Sarajevo (Nurković, 2005). According to dynamics of increase in jobs some other, primarily municipal centres distinguish themselves.

These are, for example, Zenica 101\%, Tešanj $112 \%$, Travnik $76 \%$, Brčko 109\%, and Bijeljina $107 \%$. It is about smaller work centres in which industrial facilities are built or other economic activities are developing. The strongest work centres, besides Sarajevo, Tuzla, Banja Luka, and Mostar had lower increase in employment, fewer than $50 \%$. However, this isn't a consequence of their slower development, but similar to Sarajevo, of certain tendencies of decentralisation.

The presented data on significance of work function and increase in number of employed people in the work centres indicate polarisation in distribution of jobs in Bosnia and Herzegovina. In addition to Sarajevo, 
respectively its agglomeration, according to importance of work function seven centres are distinguished: Tuzla, Banja Luka, Mostar, Doboj, Zenica, Bihać, and Brčko (see Figure 1).

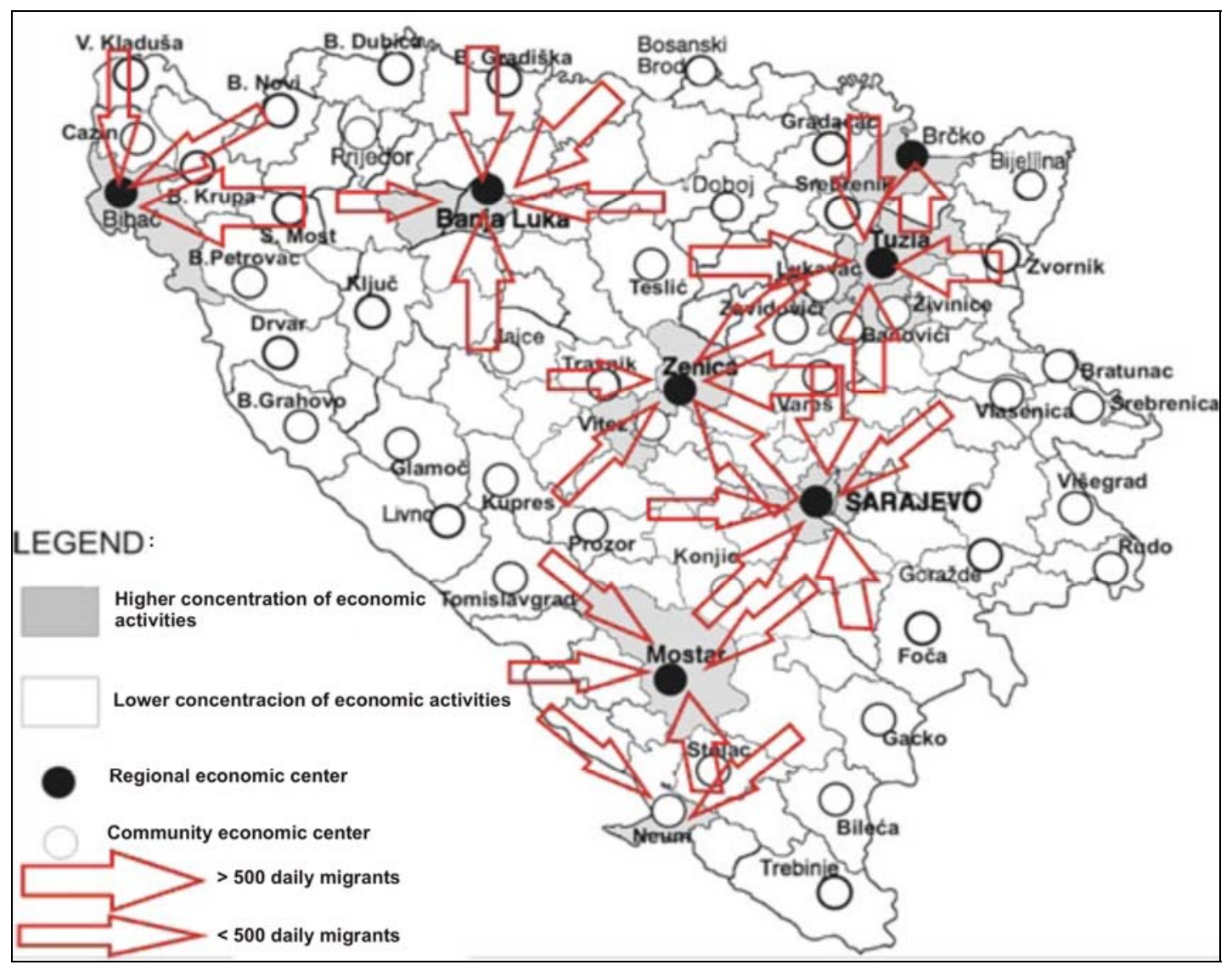

Figure 1. Regional economic centres in Bosnia and Herzegovina in 2011. Source: Nurković (2011).

Employment of agricultural population in industry and other activities has social and spatial mobility as a consequence, as it has already been emphasised. The latter can be manifested in two main forms: in permanent moving the population into work centres or daily movement of population more than 500 daily migrants. The mentioned forms of spatial mobility of population affect the adequate urbanisation forms (Ilbery, 1998).

Relation of intensity of one and the other form of spatial mobility may serve as a measure of the level of development and urbanisation of Bosnia and Herzegovina. Namely, it is known that in the first stages of industrialisation of every country, permanent moving the population exceeds a daily mobility, whereas in the mature stage of industrialisation permanent moving weakened and almost stopped and daily migrations strengthened. Daily migrations are in increase, not only in entire country, but also in Bosnia and Herzegovina. Share of daily migrants in Bosnia and Herzegovina increased from 31.2\% in 2010 to $35.5 \%$ in 2011.

In our opinion, two major factors influenced creating the existing, in some elements specific gravitational areas. The first is proximity, respectively accessibility of work centre. Due to possibility of daily movements to work there was no stronger moving the population from the surroundings of work centres: on the contrary, single settlements from the surroundings became attractive for settling. The second factor originates, in our opinion, from community organisation of our country. 
Community organisation system influenced much on forming the gravitational relations in different fields of life and in work relations as well. Due to mentioned factors, the zone of more intensive daily migration of employed people is within the territory of municipalities. Strict congruence between the zone of the most intensive migration and boundary of municipalities of the most municipal centres directly indicates that, in addition to proximity and higher accessibility (by foot, by bike, by motorbike, by bus, by car) the mentioned political factor also influenced the migration (Lloyd \& Dicken, 1972).

Economic development of Bosnia and Herzegovina was different in single periods of its socio-economic development. Dependence was the highest when Bosnia and Herzegovina had the lowest level of development and lower, naturally, as development was getting more dynamical and diversified. Historical development of Bosnia and Herzegovina shows that it has been a backward and undeveloped area for centuries.

It is closed by ranges of high mountains, which affected a poor urban development. In these social conditions economic operations were directly related to exploitation of natural resources at a very low level of processing. Extensive economic development, whose economic structure insignificantly changed over the time, was characteristic of almost whole period of development of Bosnia and Herzegovina.

\section{Urban Population of Bosnia and Herzegovina}

Urbanized population has rather high growth rates in the whole period. The reached level of urbanisation in 2011 (according to criterion by which inhabitants of the settlements bigger than 2,000 inhabitants are regarded as urbanised) of $49.5 \%$, shows that Bosnia and Herzegovina classified into countries having a medium level of urbanisation.

An accelerated development of urbanisation in the period from 1991 to 2010 may be attributed to significantly greater role of smaller settlements that become secondary centres in the municipalities, which is in accordance with the proclaimed principles of polycentric development that is supported also by the first generation of spatial plans of municipality. Active population share in a group of settlements from 400-600 active inhabitants was $4.9 \%$, settlements up to 200 active inhabitants $4 \%$ and $3.8 \%$ settlements with $200-400$ active inhabitants (see Table 2 and Figure 1).

The highest growth of settlements was achieved in a group of settlements with 2,001-10,000 inhabitants, and the highest demographic growth achieved the settlements in the group from 50,001-100,000 inhabitants. The previous trends of the observed phenomena, as well as their anticipated development, indicate that in the area of Bosnia and Herzegovina there is a simultaneous tendency of concentration, as well as certain forms of dispersion. On the one hand, that dispersion is a consequence of the form of settling in numerous (around 5,800) scattered rural settlements that are abandoned every day, but also keep significant share of population. On the other hand, a sufficiently dense network of the centres that represent points in space at which social efforts for more equal development are crystallised is developed.

However, in order to familiarize ourselves more objectively with urban structure of city settlements in Bosnia and Herzegovina, four criteria were applied. These are size of settlement, share of agricultural population, share of households without agricultural household and share of employed workers and share of employed workers of given settlement in total number of employed workers.

Parameters in the model have not been selected accidentally, but are the result of the conducted analysis. By 
means of the mentioned models in Bosnia and Herzegovina in 1991, by using census data, five urban settlements in which $45 \%$ population live were separated. In the structure of urban settlements according to size, total of 34 settlements up to 4,999 inhabitants were dominant. There were 48 medium-sized urban settlements from 5,000 to 19,999 inhabitants, whereas two urban settlements had more than 100,000 inhabitants. In five largest urban settlements of Bosnia and Herzegovina there used to live $16.72 \%$ of urban population, respectively $38.2 \%$ of total population (see Table 2).

Table 2

Structure of Urban Population of Bosnia and Herzegovina According to Size of Urban Settlements, 2011

\begin{tabular}{lccccc}
\hline $\begin{array}{l}\text { Size of urban settlements according } \\
\text { to number of inhabitants }\end{array}$ & $\begin{array}{l}\text { Number of urban } \\
\text { settlements }\end{array}$ & $\begin{array}{l}\text { \% of total } \\
\text { number }\end{array}$ & $\begin{array}{l}\text { Number of } \\
\text { inhabitants }\end{array}$ & $\begin{array}{l}\text { \% of total urban } \\
\text { population }\end{array}$ & $\begin{array}{l}\text { \% of total active } \\
\text { population }\end{array}$ \\
\hline 100,000 and more & 4 & 4.0 & 980,000 & 29.9 & 6.9 \\
$20,000-99,999$ & 15 & 3.0 & 870,000 & 26.6 & 56.4 \\
$5,000-19,999$ & 55 & 1.1 & 780,000 & 23.8 & 23.3 \\
$2,000-4,999$ & 42 & 2.1 & 640,000 & 19.5 & 13.4 \\
Total & 116 & 100 & $3,270,000$ & 100 & 100 \\
\hline
\end{tabular}

Economic and general development of the spaces with small and scattered settlements requires a developed traffic infrastructure. Favourable traffic infrastructure in Bosnia and Herzegovina still does not exist. There is an aspiration that functions are spatially divided as much as possible during development of rural areas, respectively that functionally cleaner areas are created.

Despite the efforts to create mono-functional areas, functionally mixed areas are still dominant in rural areas of Bosnia and Herzegovina. Changes in significance of rural areas within some countries and single functional areas within specific rural area can be noticed by comparing the number of urban population and rural areas or by analysing the population structure.

High economic growth is certainly a result of strong development of economic activities in Bosnia and Herzegovina, and in particular industry, which lead to essential changes in the structure of BH economy and urban development.

What regularly happens in processes of economic progress based on industrialisation, happened also in Bosnia and Herzegovina, in such a manner that this country essentially changed the structure of economic operations, and the agriculture and other primary activities participated much less in creating the social wealth. In the structure of economic development very dynamical changes have been shown, in the sense of expressed strengthening the secondary sector of economic operations, while tertiary sector did not develop in adequate measure.

Transforming the economic structure in direction of achieving greater modernization of development was considerably below the achieved modernization in developed capitalist countries. Namely, in West European countries primary sector makes only 5 to 6 percent of social product, secondary around $40 \%$, while a significantly more developed tertiary sector of economy makes more than $50 \%$ of social product of total economy.

\section{Conclusion}

Interdependence of urbanisation forms and spatial mobility of population in Bosnia and Herzegovina is clearly expressed. Permanent moving the population to work centres still has a great importance in urban development. This induces further concentration and development of existing centres. A positive feature in such 
development is noticed in slower growth of larger cities (Sarajevo, Banja Luka, Tuzla, and Mostar) with certain tendencies of decentralisation, which is clearly expressed at Sarajevo. Satellite towns of Sarajevo experience faster development, as well as some smaller centres. The constant moving shows the tendency of decrease, and daily migrations get stronger. They improve development of urbanised zones.

High economic growth is undoubtly a result of strong development of economic activities in Bosnia and Herzegovina and particularly the industry, which leads to essential changes in the structure of BH economy and urban development. What regularly happens in processes of economic progress based on industrialisation happened also in Bosnia and Herzegovina, in such a manner that this country essentially changed the structure of economic activities, and agriculture and other primary activities participated much less in creating the social wealth.

\section{References}

Ilbery, B. (1998). The geography of rural change. London: Addison Wesley Longman Limited.

Lloyd, P. E., \& Dicken, P. (1972). Location in space: A theoretical approach to economic geography. Harper.

Lorber, L. (2009). Transition in Slovenian rural areas. Revija za geografijo_Journal for Geography, 4-1.

Nurković, R. (2005). Influence of industry on urban development and infrastructure of central settlements of the Tuzla valley (pp. 355-364) (University in Belgrade, Faculty of Geography. Institute of Area Planning, Almanac, Belgrade).

Pacione, M. (2001). Urban geography—A global perspective. London: Routledge.

Ptacek, P. (2008). Institutional framework and typology of economic transition in post-communist countries of Central and Eastern

Europe: The role of Bretton Woods institutions. Journal for Geography, 1-3, 81-92.

Statistics annual/Chronicle of the Federation of Bosnia and Herzegovina (p. 24). (2000). Sarajevo.

Vresk, M. (1990). Bases of urban geography (pp. 76-84). Zagreb. 